\title{
EFFECT OF WORKING POSTURE ON OCCURRENCE OF MUSCULOSKELETAL DISORDERS AMONG THE SAND CORE MAKING WORKERS OF WEST BENGAL
}

\author{
Somnath Gangopadhyay, Tirthankar Ghosh, Tamal Das, Goutam Ghoshal, Banibrata Das \\ Ergonomics Laboratory, Department of Physiology, University College of Science and Technology, University of Calcutta, India
}

\begin{abstract}
SUMMARY
The sand core making process is performed manually in West Bengal involving a large number of workers of lowest economic strata. The core making workers most often work for a prolonged period of time and they are forced to handle various amounts of heavy load during the entire period of work.

In this study an attempt was made to identify the work related musculoskeletal disorders among the sand core-making workers. Fifty male workers engaged in carbon dioxide and chemical core making work at an unorganized sector at Baruipur, Calcutta were randomly selected for this study. A detailed modified Nordic questionnaire study on discomfort feeling was performed among the core making workers. REBA method was applied to analyze the working posture. Finally, discomfort level and risk level of the individual working postures were calculated by the use of risk level and discomfort level scale.

From the questionnaire study itwas revealed that most of the core making workers grind often in awkward postures. The workers were affected by musculoskeletal disorders like pain at low back (100\%), hand (40\%), shoulder (30\%), wrist (20\%) and neck (20\%). It has been also found that there is a significant $(p<0.05)$ correlation between discomfort level and risk level of the individual working postures of the workers.

It was concluded from the study thathealth of the core-making workers was highly affected by different awkward postures and that they suffer from posture-related musculoskeletal disorders primarily affecting the low back region.
\end{abstract}

Key words: sand core, musculoskeletal disorders, posture, discomfort level, risk level

Address for correspondence: S. Gangopadhyay, 13, Katua Kuthi Lane Bhawanipur, Calcutta: 700 025, India. E-mail: ganguly1961@ yahoo.com

\section{INTRODUCTION}

Musculoskeletal disorder (MSD) is commonly caused by overexertion, muscle strain and repetitive strain. The risk of disorder is also directly related to the number and speed of movements and the amount of force exerted with each movement. A task with high repetition and poor postures may result in a significant number of complaints or injuries (1). Awkward or extreme postures are less efficient than postures keeping joints near the center of their range of motion. A person working in an extreme or awkward posture will have to use more force to accomplish the same amount of work compared to using a neutral posture, which in turn affects muscle loading and compressive forces on the internal vertebral disc $(2,3)$. The amount and quality of forward-bent posture and the techniques of work influence the compressive force on the vertebral discs and the electromyography of erector spine muscles (2). Studies of Jonsson et al. (4), Kilbom et al. (5), Kilbom and Persson (6), dealt with the same cohort; female electronics workers followed for 3 successive years. These studies found significant association between posture variables and neck MSD. A study by Ohlsson et al. (7) compared female industrial workers performing repetitive tasks to referents without such exposure and found significant associations $(p<0.05)$ between neck and neck/shoulder diagnoses with time spent in neck flexion, with critical angles greater than $15^{\circ}$; and neck/shoulder diagnoses and time spent with upper arm abduction greater than $60^{\circ}$. Sakakibara et al. (8) found a significant positive association between posture and neck MSD among the orchard workers. The prospective study by Veiersted and Westgaard (9) followed the development of trapezius myalgia among 30 female chocolate manufacturing workers. Seventeen workers developed the MSD within 6 to 51 weeks of starting work. Perceived strenuous postures on the assembly line were found to contribute to the disorders.

In India sand core making is a very hazardous process wherein a large number of workers are directly involved. The entire core making operation is performed manually and the methods adopted are quite primitive ones. Consequently the operation is time consuming and hence the overall daily productivity is low. Moreover the workers have to work long hours and suffer from musculoskeletal disorders (10). Thus in this study an attempt was made to evaluate the effect of postures on occurrence of musculoskeletal disorders among the sand core making workers of West Bengal.

\section{MATERIALS AND METHODS}

Two types of cores are prepared by the sand core making workers of West Bengal - the carbon dioxide sand core and the chemical sand core. In carbon dioxide sand core making, the dry sand is mixed with sodium silicate and this mixture is poured into a wooden core box manually. Then carbon dioxide gas is passed 
through the sand to harden it. Finally the core box is turned upside down manually.

In chemical sand core making, the dry sand is mixed with resin, accelerator and catalyst. Then the mixture is poured into a wooden core box manually and left for hardening. Finally the core box is turned upside down manually.

Selection of Subjects: Fifty male workers engaged in carbon dioxide and chemical sand core making operation at a coremanufacturing factory in West Bengal, India were randomly selected for this study. All the subjects had a minimum working experience of five years.

Assessment of Physical Parameters: The heights and weights of the subjects participated in the study was recorded and the body mass indices were calculated (Table 1).

Table 1. Physical characteristics of sand core making workers

\begin{tabular}{|l|c|c|}
\hline Variables & Mean & SD \\
\hline Age (years) & 27.17 & 7.05 \\
\hline Height $(\mathrm{cm})$ & 162.47 & 4.95 \\
\hline Weight $(\mathrm{kg})$ & 53.65 & 6.44 \\
\hline
\end{tabular}

Questionnaire Method: Modified Nordic Questionnaire (11) was used for this study. The questionnaire consists of a series of objective-type questions with multiple-choice responses. The questions were grouped into the following major sections dealing with:

- General information of the workers.

- Work organization and work behaviors.

- Assessment of stress at work and detailed question on workrelated pain.

Each subject was approached by the researcher and was explained the aim of the study in a layman's term. Only on acceptance from the subject, the interview based on the questionnaire started.

Analysis of Working Posture: The maintenance of posture and the support of load are particular examples of static work. To analyze posture, measurement of the angles between the body parts, distribution of masses of body parts, the forces exerted on the environment during the posture, the length of the time during which specific posture is held and the effect on the person should be taken into account. The present study was carried out with REBA method.

Rapid entire body assessment (REBA) was proposed by Hignett and McAtamney (12) as a means to assess posture for risk of work related musculoskeletal disorders (WRMSDs). Consider critical tasks of a job. For each task, assess the posture factors by assigning a score to each region.

Discomfort Level Scale: Discomfort Level Scale is a ten point scale for discomfort and pain sensation, where 0 represented 'no discomfort at all' and 10 represented 'Worst discomfort (extremely uncomfortable and very painful)'. This scale was used for identifying the discomfort level of the workers in their different postures.

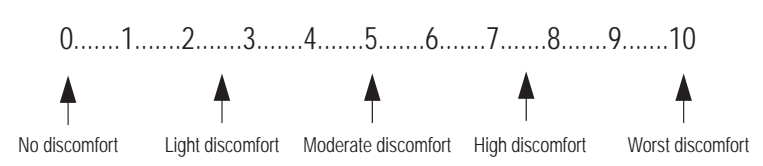

Risk Level Scale: Risk Level Scale is a ten point scale for assessment the level of risk in working posture, where 1 represented 'no risk or negligible' and 10 represented 'very high risk'. After performing REBA method on different postures of the workers, the result of the posture analysis was compared with the scale. By this we can show the risk level as numerical character.

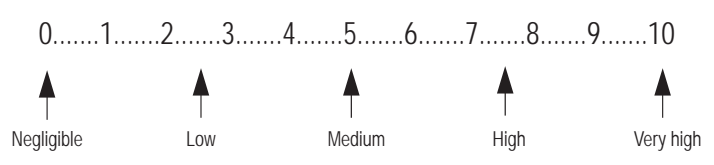

Statistical Analysis: For the statistical analysis of the variables' results, linear correlation and regressions were performed to explore the magnitude and direction of association between two variables. Statistical analysis was performed using the statistical package PRIMER OF BIOSTATISTICS (Primer of Biostatistics 5.0.msi, Msi Version = 1.20.1827.0, Primer for Windows, McGraw-Hill).

\section{RESULTS}

The mean age of the workers was $27.17 \pm 7.05$ years. The body height and body weight were $162.47 \pm 4.95 \mathrm{~cm}$ and $53.65 \pm 6.46 \mathrm{~kg}$, respectively. The workers in sand core making worked for 10.5 hours per day, starting from $10 \mathrm{AM}$ with an interval of $1.5 \mathrm{~h}$ (2.30 PM-3.30 PM) and a day off per week (Table 2). The analysis of questionnaire revealed that most of them frequently change their place while at work. This mobility allowed them to take short rest pauses that helped them relieve their job monotony. The workers often work in groups. They were required to lift 40-70 $\mathrm{kg}$ of core at a time with a constant forward bending posture with twisted back and arms. In a single day, they lifted at least 70 carbon dioxide sand cores and 50 chemical sand cores. The complaints of low-back pain can be attributed to the strenuous activities undertaken by them.

Analysis of postures (Table 3) of the workers revealed that most of the postures are highly risky and require correction as soon as possible, as indicated by REBA Decision (by comparing REBA score with REBA risk level). The workers adopted awkward postures at work, and often suffered from musculoskeletal complaints and low back pain.

Table 2. Mean duration of work and rest per day with average number of working days in a week

\begin{tabular}{|l|c|c|}
\hline $\begin{array}{l}\text { Duration of work } \\
\text { per day (in hours) }\end{array}$ & $\begin{array}{c}\text { Duration of rest } \\
\text { per day (in hours) }\end{array}$ & $\begin{array}{c}\text { Number of work- } \\
\text { ing days in a week }\end{array}$ \\
\hline 10.5 & 1.5 & 6 \\
2.11 & 1.00 & \\
\hline
\end{tabular}


Table 3. Analysis of working posture of the sand core worker by REBA

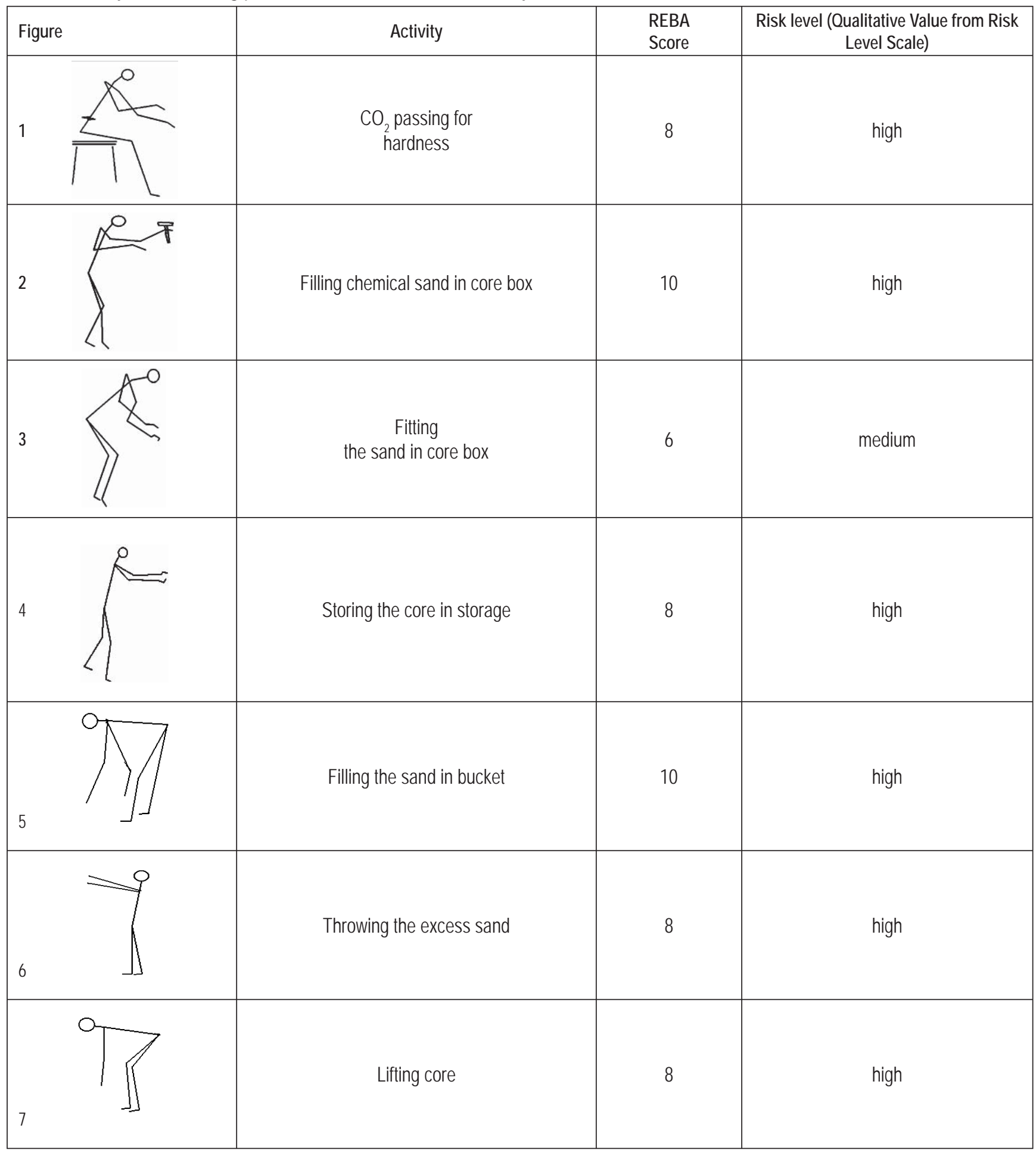

During questionnaire study, 80\% Sand Core Workers reported feeling of discomfort and among them $70 \%$ felt discomfort during work and 30\% during rest (Table 4). The feeling of discomfort in different body parts of the workers is shown in the Table 5. It is observed that the feelings of discomfort were mainly related to musculoskeletal disorders like pain at low back (100\%), hand (40\%), shoulder (30\%), wrist (20\%) and neck (20\%).

Discomfort level and risk level of the individual working postures were calculated by using the risk level scale and discomfort level scale. Linear Correlation between risk level and discomfort level in different postures of sand core workers was performed to explore the magnitude and direction of association between two variables. By the statistical analysis of these data it was found that there is a significant $(\mathrm{p}<0.05)$ correlation between discomfort level and risk level of the individual working postures (r: 0.9058, t: 4.781) (Table 6). 
Table 4. Discomfort feeling during work and during rest of sand core workers

\begin{tabular}{|l|c|c|c|}
\hline \multirow{2}{*}{$\begin{array}{l}\text { Sand core } \\
\text { workers }\end{array}$} & $\begin{array}{c}\text { Discomfort } \\
\text { feeling }\end{array}$ & $\begin{array}{c}\text { Discomfort feeling } \\
\text { during work }\end{array}$ & $\begin{array}{c}\text { Discomfort feeling } \\
\text { during rest }\end{array}$ \\
\cline { 2 - 4 } & $40(80 \%)$ & $35(70 \%)$ & $15(30 \%)$ \\
\hline
\end{tabular}

Table 5. Discomfort feeling at different body parts

\begin{tabular}{|l|c|c|c|c|c|}
\hline Body parts & shoulder & hand & wrist & neck & $\begin{array}{c}\text { low } \\
\text { back }\end{array}$ \\
\hline $\begin{array}{l}\text { Discomfort } \\
\text { feeling }\end{array}$ & $15(30 \%)$ & $20(40 \%)$ & $\begin{array}{c}10 \\
(20 \%)\end{array}$ & $\begin{array}{c}10 \\
(20 \%)\end{array}$ & $\begin{array}{c}50 \\
(100 \%)\end{array}$ \\
\hline
\end{tabular}

Table 6. Linear correlation between risk level and discomfort level in different postures of sand core workers

\begin{tabular}{|c|c|c|}
\hline Figure & $\begin{array}{c}\text { Risk level (Quantitative value } \\
\text { from Risk Level Scale) }\end{array}$ & $\begin{array}{c}\text { Discomfort } \\
\text { level }\end{array}$ \\
\hline 1 & 7.5 & 8 \\
\hline 2 & 7.5 & 9 \\
\hline 3 & 5 & 6 \\
\hline 4 & 7.5 & 9 \\
\hline 5 & 7.5 & 9 \\
\hline 6 & 7.5 & 9 \\
\hline 7 & 7.5 & \\
\hline r value & \multicolumn{2}{|c|}{0.9058} \\
\hline t value & 4.781 \\
\hline \multicolumn{2}{|c|}{} \\
\hline
\end{tabular}

\section{DISCUSSION}

From the investigation it can be concluded that the core making is a grinding work and workers have most often to work in awkward postures, so naturally they suffer from various musculoskeletal disorders primarily affecting the low back region.

On consideration of the above facts and the hazardous postures that require correction as soon as possible as indicated by REBA Decision, recommendations like changing the working level or height (to avoid the stooping posture) by using platform can be made to improve some of the working postures that need correction in the near future. The workers are primarily using the stooping posture and handling heavy load - thereby generating musculoskeletal disorders. This statement has been supported by a number of workers suffering from musculoskeletal disorders like pain in different body parts. Choobineh et al. (13) also found that carpet weavers are suffering from musculoskeletal problems mainly attributed to poor working postures.

A significant $(\mathrm{p}<0.05)$ correlation between discomfort level and risk level of the individual working postures also prove that the sand core workers are affected by musculoskeletal disorders that is mainly caused due to adoption of awkward working postures. Moreover, they have to work for prolonged period of time

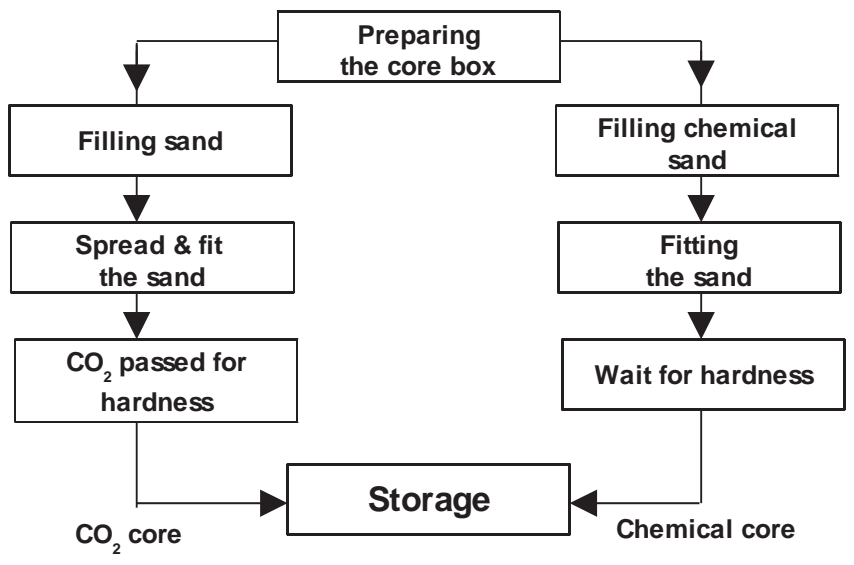

Fig. 1. Flow chart of the sand core making process.

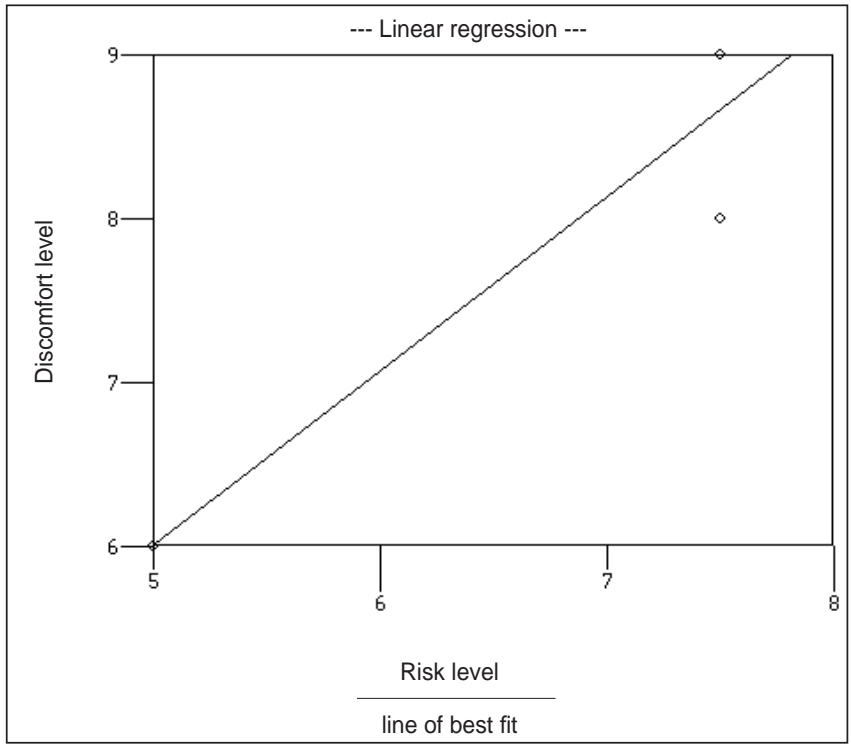

Fig. 2. Linear regression between risk level and discomfort level in different postures of sand core workers.

remaining in such constrained awkward postures, which further amplifies their discomfort feeling.

\section{CONCLUSIONS}

It can be concluded from the study that health of the sand core-making workers was highly affected by different awkward postures and they suffer from posture-related musculoskeletal disorders primarily affecting the low back region.

\section{REFERENCES}

1. Bernard BP, editor. Musculoskeletal disorders and workplace factors: a critical review of epidemiologic evidence for work-related musculoskeletal disorders of the neck, upper extremity, and low back. NIOSH Publication No. 97-141. Cincinnati (OH): U.S. Department of Health and Human Services, Public Health Service, Centers for Disease Control and Prevention, National Institute for Occupational Safety and Health; 1997.

2. Anderson CK, Chaffin DB, Herrin GD. A study of lumbosacral orientation under varied static loads. Spine. 1986 Jun;11(5):456-62.

3. McGill SM, Norman RW. Dynamically and statically determined low back moments during lifting. J Biomech. 1985;18(12):877-85. 
4. Jonsson BG, Persson J, Kilbom A. Disorders of the cervicobrachial region among female workers in the electronics industry: a two-year follow-up. Int J Ind Ergon. 1988;(3):1-12.

5. Kilbom A, Horst D, Kemfert K, Richter A. Observation methods for education of load and strain on the human body - a review. Abetarskyddsstyrelsen Publikation Serv. 1986;171(84):92.

6. Kilbom A, Persson J. Work technique and its consequences for musculoskeletal disorders. Ergonomics. 1987 Feb;30(2):273-9.

7. Ohlsson K, Attewell RG, Pålsson B, Karlsson B, Balogh I, Johnsson B, et al. Repetitive industrial work and neck and upper limb disorders in females. Am J Ind Med. 1995 May;27(5):731-47.

8. Sakakibara H, Miyao M, Kondo T, Yamada S, Nakagawa T, Kobayashi F. Relation between overhead work and complaints of pear and apple orchard workers. Ergonomics. 1987 May;30(5):805-15.

9. Veiersted KG, Westgaard RH. Subjectively assessed occupational and individual parameters as risk factors for trapezius myalgia. Int J Ind Ergon. 1994;13(3):235-45.
10. Gangopadhyay S, Das T, Ghoshal G, Ghosh T. Work organization in sand core manufacturing for health and productivity. Int J Ind Ergon. 2006 Oct;36(10):915-20.

11. Kuorinka I, Johnson B, Kilbom A, Vinterberg H, Biering-Sørenson F, Andersson G, et al. Standardised Nordic questionnaires for the analysis of musculoskeletal symptoms. Appl Ergon. 1987 Sep;18(3):233-7.

12. Hignett S, McAtamney L. Rapid entire body assessment (REBA). Appl Ergon. 2000 Apr;31(2):201-5.

13. Choobineh A, Lahmi M, Hosseini M, Shahnavaz H, Jazani RK. Workstation design in carpet hand-weaving operation: guidelines for prevention of musculoskeletal disorders. Int J Occup Saf Ergon. 2004;10(4):411-24.

Received June 9, 2008 Accepted in revised form June 10, 2009 